IZA DP No. 5332

Tacit Lobbying Agreements: An Experimental Study

Jens Großer

Ernesto Reuben

Agnieszka Tymula

November 2010 


\title{
Tacit Lobbying Agreements: An Experimental Study
}

\author{
Jens Großer \\ Florida State University \\ Ernesto Reuben \\ Columbia University \\ and IZA
}

Agnieszka Tymula

New York University

Discussion Paper No. 5332

November 2010

IZA

P.O. Box 7240

53072 Bonn

Germany

Phone: +49-228-3894-0

Fax: +49-228-3894-180

E-mail: iza@iza.org

Any opinions expressed here are those of the author(s) and not those of IZA. Research published in this series may include views on policy, but the institute itself takes no institutional policy positions.

The Institute for the Study of Labor (IZA) in Bonn is a local and virtual international research center and a place of communication between science, politics and business. IZA is an independent nonprofit organization supported by Deutsche Post Foundation. The center is associated with the University of Bonn and offers a stimulating research environment through its international network, workshops and conferences, data service, project support, research visits and doctoral program. IZA engages in (i) original and internationally competitive research in all fields of labor economics, (ii) development of policy concepts, and (iii) dissemination of research results and concepts to the interested public.

IZA Discussion Papers often represent preliminary work and are circulated to encourage discussion. Citation of such a paper should account for its provisional character. A revised version may be available directly from the author. 
IZA Discussion Paper No. 5332

November 2010

\section{ABSTRACT}

\section{Tacit Lobbying Agreements: An Experimental Study ${ }^{*}$}

We experimentally study the common wisdom that money buys political influence. In the game, one lobbyist has the opportunity to influence redistributive tax policies in her favor by transferring money to two competing candidates. The success of the lobbying investment depends on whether or not the candidates are willing to respond and able to collude on lowtax policies that do not harm their relative chances in the elections. In the experiment, we find that lobbying is never successful when the lobbyist and candidates interact just once. By contrast, it yields substantially lower redistribution in about $40 \%$ of societies with finitelyrepeated encounters. However, lobbying investments are not always profitable, and profitsharing between the lobbyist and candidates depends on prominent equity norms. Our experimental results shed new light on the complex process of buying political influence in everyday politics and help explain why only relatively few corporate firms do actually lobby.

JEL Classification: $\quad$ D72, H10, K42

Keywords: lobbying, redistribution, elections, bargaining, collusion

Corresponding author:

Ernesto Reuben

Columbia Business School

3022 Broadway

Uris Hall

New York, NY 10027

USA

E-mail: ereuben@columbia.edu

\footnotetext{
* We are grateful for financial support from the GEW Foundation Cologne and the German Science Foundation.
} 
Lobbying is big business! For example, in the United States 13,694 registered lobbyists spent $\$ 3.49$ billion on influencing congressmen and federal agencies in 2009, and this amount has been rising steadily over the past decade-for comparison, 10,405 registered lobbyists spent $\$ 1.44$ billion in $1998 .{ }^{1}$ Moreover, lobbying expenditures dwarf campaign contributions and other political donations (Milyo, Primo, and Groseclose 2000). ${ }^{2}$ The vast and growing business of buying political influence, the details of which are often invisible to outsiders, can affect economic welfare and redistribution in an order of magnitude that in all likelihood exceed the lobbying costs (Stigler 1971). It is commonly perceived that lobbying is a financial investment in the political marketplace (according to Stigler 1971, there is a "demand" for regulation by corporate firms and a "supply" by policymakers). In other words, corporate firms that lobby must be doing so because they anticipate it will deliver enough benefits to recoup its costs. ${ }^{3}$ Examples of lobbying costs include, but are not limited to, costs of monitoring and meeting with policymakers, providing testimony for congressional hearings, research, and technical information (Schlozman and Tierney 1983; Heinz et al. 1993; Nownes and Freeman 1998), bribes (Dal Bó 2007), and payments to registered expert lobbyists. In return for their investments, lobbying firms receive benefits such as subsidies and tax breaks.

In this paper, we use game theory and laboratory experimentation to study lobbying as a tacit collusion and bargaining process that delivers profits to the involved triad-a corporate firm and two competing political candidates-at the expense of a majority of voters. If the lobbyist and candidates seek to collude, they must overcome various

\footnotetext{
1 The Center for Responsive Politics: http://www.opensecrets.org/lobby/ (September 1, 2010).

2 Milyo, Primo, and Groseclose (2000) find that the politically influential industries of tobacco, pharmaceuticals, telephone utilities, defense aerospace, and computers allocated between $92 \%$ and $95 \%$ of their total political expenditures to lobbying in 1997 and 1998. Similarly, Richter, Samphantharak, and Timmons (2009) report that lobbying accounted for nearly 85\% of total registered political expenditures in the period 1998 to 2005.

3 The investment perspective of lobbying originates from Ben-Zion and Eytan (1974), Stigler (1971), Tullock (1972), and Welch (1974), who coined the terminology of "quid pro quo" political contributions. For a survey on rational-choice models of interest groups including rent-seeking models see Mitchell and Munger (1991).
} 
challenges due to the complexity and uncertainties involved in reaching lobbying agreements. For one thing, complexity arises because there are many decision makers involved (e.g., lobbyists, candidates, and voters), and all of them pursue a variety of common or opposing interests (e.g., tax favors for lobbyists may hurt the general electorate). For another, complexity arises because lobbying agreements are not contract-enforceable, i.e., neither the lobbyist nor the candidates can be held accountable by law if they renege on promises given upon receiving favors. Rather, lobbying agreements are usually implicit and require mutual trust and reciprocation.

We present and analyze a game that captures some of the important strategic incentives in the lobbying process (henceforth the lobbying game). It includes one lobbyist, two competing candidates, and a set of voters. In the first stage, the lobbyist decides on whether and how much money to transfer to each candidate. In the second stage, the two candidates choose tax policies under the shadow of an upcoming simple-majority election (third stage). Candidates have a pecuniary interest in winning the election, and the tax policy of the winner determines the amount of money that is redistributed from the lobbyist to the majority of voters (i.e., the lobbyist's most favorable outcome is zero redistribution while the majority's is full redistribution). ${ }^{4}$ Note that candidates are not contractually obligated to change their tax policy because of the lobbyist's transfers. We are interested in explaining the emergence and stability of tacit lobbying agreements, defined as mutually profitable exchanges of transfers and tax favors where those involved cannot write enforceable contracts and can communicate only through observed decisions.

To reach a tacit lobbying agreement, the lobbyist must trust her money to the two candidates, which is risky as there is no guarantee they are willing or able to return the favor. For example, having just one civic-minded candidate who cannot be coaxed to lower her tax policy ruins the lobbying investment. Moreover, even if willing, candidates might be

\footnotetext{
4 We consider the effects of lobbying on redistribution since it is sufficient to create a tension between the lobbyist and the majority. An alternative model would have been to consider the effects of lobbying on economic growth. Also, we use only one lobbyist since firms often lobby individually for "private goods" rather than jointly as industries for "public goods" (Hansen, Mitchell, and Drope 2005).
} 
unable to coordinate on low-tax policies. Any lack of coordination in tax policies will hurt the candidate with the lower tax (since a majority prefers the higher tax), which makes reciprocation of lobbying transfers risky. On the other hand, if they manage to coordinate on low-tax policies, the lobbyist and candidates can continue to benefit as long as the former keeps making transfers and the latter keep taxes low (Ben-Zion and Eytan 1974). In this respect, the lobbyist's decision of how much to transfer to each candidate is crucial for successful policy coordination (Bental and Ben-Zion 1975). ${ }^{5}$ Overall, we think that the challenges of mutual trust and reciprocation in our setup are representative of important incentives faced by lobbyists and candidates in everyday politics.

We show that with only self-interested players and finitely many encounters (and other commonly-used assumptions), the only subgame perfect equilibrium of the lobbying game involves zero transfers and full redistribution. However, there is overwhelming empirical evidence that self-interest alone fails to predict behavior in games with incentives to cooperate and free-ride on the cooperation of others (see Fehr and Gächter 2000). One type of player is particularly important to increase joint profits: the conditional cooperator, who is willing to cooperate only if others do so too (e.g., Axelrod 1981; Fischbacher, Gächter, and Fehr 2001). Using the reasoning of Kreps et al. (1982), we argue that if players can be either self-interested or conditionally cooperative and there is incomplete information regarding the other players' types, in a sequential equilibrium, tacit lobbying agreements can emerge in a finitely-repeated lobbying game as long as lobbyists and candidates have high-enough beliefs that their respective co-colluders are conditionally cooperative. In fact, there are many possible tacit lobbying agreements with varying levels of joint profits and ways to share these profits. However, it is doubtful that each equilibrium receives (equal) support from the potential colluders. Therefore, we refine our predictions

\footnotetext{
5 Hojnacki and Kimball (1998) show empirically that resourceful lobbyists lobby both allied and opponent congressmen (as well as undecided legislators). In contrast, our lobbyist does not have a priori preferences for either of the two candidates. In this sense, their finding provides strong empirical support for a lobbyist's incentives to simultaneously woo competing policymakers.
} 
by using a prominent equity norm that is suitable to our game and has empirical support in bargaining situations: i.e., split-the-difference (see Selten 1987).

Whether or not repeated interaction is necessary for tacit lobbying agreements to emerge is an important question (e.g., Snyder 1992; Snyder and Ting 2008). ${ }^{6}$ To tackle this question, we compare situations where decision makers meet once and repeatedly for a finite number of periods. With one-shot encounters, tacit lobbying agreements can emerge in the lobbying game if both candidates are conditional cooperators and the lobbyist and candidates believe so with sufficiently-high probability. With repeated encounters, there is potential for the emergence of more lobbying agreements because reciprocation is also available to the lobbyist (i.e., she can use transfers in subsequent periods to "reward" or "punish" tax policies), which gives self-interested candidates an incentive to collude for at least some periods.

The profitability of lobbying has been examined by only a few observational studies. De Figueiredo and Silverman sum up: "Despite 65 years of theoretical and empirical investigation, and a steadily increasing interest by the press and electorate, there are no large-scale statistical studies of the returns to lobbying" $(2006,598)$. The main reason for this gap in the literature is the challenge associated with defining and measuring the costs and benefits of lobbying (e.g., even experts tend to disagree on the exact value of information, subsidies, tax breaks, and other units of political favors). In addition, appropriate data are scarcely available due to the lobbying coalition's incentives to avoid public scrutiny. However, there are some exceptions. For example, De Figueiredo and Silverman (2006) find that a $10 \%$ increase in lobbying by a university represented in a House or Senate Appropriations Committee increases the university's earmarks by 3.5\%. In another example, Richter, Samphantharak, and Timmons (2009) use data available from the Center for Responsive Politics and report that for an average corporate firm spending 1\%

\footnotetext{
${ }^{6}$ In the words of Milyo, Primo, and Groseclose: "In the absence of such [enforceable] contracts, it is difficult to understand how a 'spot market' for political favors can exist. In a simple one-period model (absent of perfectly simultaneous exchange) either contributors or legislators will surely renege on the deal, so no deals are ever made" $(2000,80)$.
} 
more on registered lobbying decreases the firm's effective tax rate between 0.5 and 1.6 percentage-points (in absolute amounts, each $\$ 1$ invested yields returns from $\$ 6$ to $\$ 20$ ). However, in spite of these gains only about $10 \%$ of firms choose to lobby. Our paper is an important complement to these observational studies. In our game and laboratory experiment we control the costs and benefits from lobbying, which allows us to unequivocally measure profitability. Compared to both studies, our setup is more suitable to analyze the conditions under which lobbying agreements emerge. In the conclusions we discuss similarities between their and our results with an eye on external validity.

There are many theoretical studies that have looked at lobbying from a variety of angles. Here, we discuss the ones most closely related to our paper. ${ }^{7}$ To begin, Bental and Ben-Zion (1975) use a spatial competition model to analyze the optimal transfer decisions of a lobbyist, who can give money to two candidates (whose behavior is determined by a function) to pull their policy platforms closer to their own ideal point. In an optimum, the two symmetric or asymmetric transfers must yield equal marginal returns and depend on the distribution of the voters' and candidates' ideal points. Among other variations, the following studies use different numbers of lobbyists and policymakers. In the "protection for sale" or menu auction model of Grossman and Helpman (1994), one incumbent is lobbied by multiple industries to influence trade policy. In Hillman and Ursprung (1988) and Magee, Brock, and Young (1989) multiple lobbyists can transfer money to competing candidates with imperfectly known policy preferences, where transfer decisions optimize the chances of winning of their favorite candidates. In contrast to these models (and the two observational studies discussed earlier), we more explicitly examine the interaction between lobbying and policymaking. This introduces collusion, bargaining, and free-rider incentives to the lobbying process that are not fully accounted for in the other studies.

\footnotetext{
${ }^{7}$ For an overview see Grossman and Helpman (2001). Much of the literature studies the role of information on policymaking. Although, broadly speaking, money transfers in our lobbying game can be interpreted as the value of information, we do not explicitly examine the mechanisms of knowledge transmission between the lobbyist and candidates.
} 


\section{Lobbying game and equilibrium predictions}

In this section, we present our games and derive theoretical predictions. The lobbying game models the opportunity of a lobbyist to influence redistributive policies in her favor and in detriment of a majority of voters by transferring money to political candidates who compete in elections. Furthermore, this game is compared to a simpler model without lobbying opportunities: the redistribution game.

\section{The lobbying game}

Consider a "society" with $i=1, \ldots, n \geq 3$ voters and two candidates, $j=A, B$. Each voter $i$ has an initial income of $e_{i} \geq 0$ points, where $\bar{e} \equiv \frac{1}{n} \sum_{i=1}^{n} e_{i}$ denotes the average voter income. We assume that there is one rich voter, labeled $R$, with $e_{R}>\bar{e}$ and $n-1$ poor voters, labeled $P$, each with equal income $e_{P}<\bar{e}$. Moreover, both candidates have the same initial income of $\omega=\omega_{A}=\omega_{B} \geq 0$ points. The players take part in the following three-stage game.

\section{Lobbying stage}

In the first stage, the rich voter has the opportunity to lobby by transferring points to each candidate $j, l_{R \rightarrow j} \geq 0$, with the only restriction that $0 \leq l_{R} \leq e_{R}$, where $l_{R} \equiv l_{R \rightarrow A}+l_{R \rightarrow B}$. Importantly, transfers do not change any player's decision space in the following stages. In particular, the candidates have no obligations towards the rich voter upon receiving transfers. Note that poor voters cannot lobby.

\section{Policy stage}

In the second stage, each candidate chooses a binding redistributive tax policy, $t_{j} \in[0,1]$, which determines the degree to which the rich voter must share her income with the poor voters. ${ }^{8}$ Specifically, if candidate $j$ 's tax policy applies, each voter's after-tax income is given by $e_{i, t_{j}} \equiv e_{i}+t_{j}\left(\bar{e}-e_{i}\right)$. The two extreme cases are: zero redistribution, which does not affect incomes (i.e., $e_{R, t_{j}=0}=e_{R}$, and $e_{P, t_{j}=0}=e_{P}$ ), and full redistribution, which imposes the same income on all voters (i.e., $e_{i, t_{j}=1}=\bar{e}$ for all $i$ ). Candidates make decisions using the

\footnotetext{
8 While the terminology of rich and poor voters is convenient and mirrors their initial incomes, the lobbying game captures more generally the idea that a lobbyist can gain at the expense of a majority.
} 
following procedure: $j$ chooses her tax policy first, and $-j \neq j$ chooses her tax policy after

observing $t_{j}$. Thereafter, candidate $j$ observes $t_{-j}$ and can either accept the current pair of tax policies or change her tax policy at a (small) cost of $c=c_{A}=c_{B}>0$ points. If she accepts, the game proceeds to the third stage. If she opts for a change, candidate $-j$ observes the new $t_{j}$ and gets to either accept the current pair of tax policies or change her tax policy at a cost, and so on. The procedure only ends when a candidate accepts the pair of tax policies. We use this procedure to facilitate coordination between candidates.

\section{Election stage}

In the third stage, the accepted tax policies, $t_{A}$ and $t_{B}$, are made public and candidates compete in simple majority elections (a tie is broken randomly with equal probability for each candidate). Voters simultaneously and independently vote either for candidate $A$ or for candidate $B$ (abstention is not an option). The winning candidate, $w$, receives a bonus of $b$ points (where $\frac{b}{2}>c>0$ ), and her tax policy, $t_{w}$, determines the after-tax incomes of the voters as described above. The loser gets no bonus and her tax policy is of no consequence. Then, each candidate $j$ 's expected payoff is

$$
E\left[\pi_{j}\right]=\omega+l_{R \rightarrow j}-C_{j}+\left\{\begin{array}{l}
b \text { if } V_{j}>V_{-j} \\
\frac{b}{2} \text { if } V_{j}=V_{-j} \\
0 \text { if } V_{j}<V_{-j}
\end{array}\right.
$$

where $C_{j}$ denotes her total costs of tax policy changes and $V_{j}\left(V_{-j}\right)$ denotes the total number of votes for $j(-j)$. Moreover, the rich voter's payoff is $\pi_{R}=e_{R}-l_{R}-t_{w}\left(e_{R}-\bar{e}\right)$ and each poor voter's payoff is $\pi_{P}=e_{P}+t_{w}\left(\bar{e}-e_{P}\right)$.

\section{The redistribution game}

The lobbying game can be compared to a pure redistribution game without lobbying opportunities. In this model, we simply exclude the lobbying stage and the terms $l_{R \rightarrow j}$ and $l_{R}$ in the above payoff expressions. Comparing both games allows us to analyze the effects of lobbying opportunities on redistribution per se. 


\section{Experimental parameters}

It is helpful to introduce here the parameters used in our experimental games. A society consists of $n=4$ voters and two candidates, $j=A, B$. At the beginning of the game, the rich voter receives $e_{R}=130$ points and each poor voter receives $e_{P}=10$ points. In the lobbying game, the rich voter could transfer up to 130 points in any combination of integer numbers to the two candidates, i.e., $l_{R \rightarrow A}+l_{R \rightarrow B} \in\{0,1, \ldots, 130\}$ points. Moreover, each candidate received an income of $\omega=25$ points and the bonus for winning the election was $b=20$ points. A tax policy in the experiment is an integer percentage, $t_{j} \times 100 \in\{0,1, \ldots, 100\}$, and each tax policy change cost $c=1$ point. Net of transfers in the lobbying game, these parameters imply an average voter payoff of $\bar{e}=40$ points and an average expected candidate payoff of $\frac{1}{2} E\left[\pi_{A}\right]+\frac{1}{2} E\left[\pi_{B}\right]=35$ points.

\section{Equilibrium predictions}

In this subsection, we derive equilibrium predictions for the lobbying and redistribution games. We distinguish between situations where lobbying is prohibited or does not emerge (Prediction 1) from those where it can emerge (Predictions 2 to 4). To do so, we vary the number of interactions (one-shot vs. finitely-repeated) and the information players possess about own and others' preferences (complete vs. incomplete). Finally, we refine the predicted set of all possible tacit lobbying agreements using split-the-difference, a prominent profit-sharing norm.

First, we examine societies, assuming that everyone is self-interested regarding their own payoffs and this is common knowledge (as are all procedures and parameters of the game, including the number of interactions). ${ }^{9}$ Moreover, we use subgame perfection and refine our predictions by focusing on weakly undominated strategies in each stage of the

\footnotetext{
${ }^{9}$ For our experimental parameters, the predictions do not differ markedly when replacing universal self-interest with the assumption that some or all voters/candidates have social preferences with reference to the entire society (e.g., Fehr and Schmidt 1999, Bolton and Ockenfels 2000). This is because with tax policies close to $100 \%$, payoffs are similar across all members of the society and lower tax policies generally increase inequality. Calculations are available upon request.
} 
game and by assuming that voters who are indifferent (i.e., face identical tax policies $t_{A}=$ $t_{B}$ ) vote randomly with equal probability for each candidate. Under these assumptions, subgame perfect equilibrium yields the following prediction for the lobbying and redistribution games:

Prediction 1 (Zero transfers and full redistribution): In the one-shot lobbying game with only self-interested players, the rich voter makes zero transfers $\left(l_{R}^{*}=0\right)$, both candidates immediately choose and accept full redistribution $\left(t_{A}^{*}=t_{B}^{*}=1\right)$, and all voters vote randomly between the two candidates. The same holds for each period in the finitely-repeated lobbying game. Finally, the respective predictions are the same for the one-shot and finitely-repeated redistribution game, except that the rich voter does not make any lobbying decisions.

Proof: Available in the online appendix.

Prediction 1 serves as a benchmark. Next, we concentrate on the lobbying game and turn to situations where tacit lobbying agreements can emerge. Let us define a tacit lobbying agreement, labeled $\{R, A, B\}$, as a combination of transfers and a winning tax policy where each member of the coalition of the rich voter $R$ and both candidates $A$ and $B$ earns strictly more than in the benchmark Prediction 1. Note that any such agreement always hurts the poor voters since it reduces their proceeds from redistribution. Formally, in a tacit lobbying agreement, $\pi_{R}^{\{R, A, B\}}>\bar{e}, E\left[\pi_{j}^{\{R, A, B\}}\right]>\omega+\frac{b}{2}, j=A, B$, and $\pi_{P}^{\{R, A, B\}}<\bar{e}$. Agreements are tacit, as we allow players to communicate only through observed decisions.

A tacit lobbying coalition has the power to undermine the majority's will (assuming that it is full redistribution; cf. footnote 9), but whether or not this happens strongly depends on mutual trust and reciprocation among the rich voter and candidates. To be precise, the rich voter must trust her money to the two candidates, who must return the favor by coordinating on a winning tax policy that is sufficiently low to make the lobbying investment profitable.

To understand the emergence of tacit lobbying agreements, we examine societies where, with strictly positive probability, self-interested players coexist alongside a second type of player: conditional cooperators, who are willing to cooperate to attain higher joint 
profits as long as others do so too (Axelrod 1981; Fischbacher, Gächter, and Fehr 2001).10 Additionally, we assume that players know their own type, but they have incomplete information about the types of all other players and this is common knowledge (all other assumptions remain the same as before). ${ }^{11}$ In the analysis that follows, we are particularly interested in the possibility of collusion among the rich voter and two candidates against the majority's will of full redistribution. How can the potential presence of conditional cooperators affect our predictions? Let us first analyze this question for one-shot encounters before turning to finitely-repeated encounters. This gives our next prediction:

Prediction 2 (Tacit lobbying agreements with one-shot encounters): In the one-shot lobbying game with incomplete information about the other players' types-who are either self-interested or conditionally-cooperative-tacit lobbying agreements can occur only if both candidates are conditional cooperators and if the rich voter and candidates have high-enough beliefs of this being the case. Otherwise, we predict zero transfers and full redistribution (as in Prediction 1).

Argument: We provide intuition rather than formally deriving the sequential equilibria underlying this prediction, which is tedious but straightforward. Our definition of a tacit lobbying agreement implies a winning tax policy strictly smaller than 1. A self-interested candidate always chooses according to the will of the majority, $t_{j}=1$, since in a one-shot game she cannot be rewarded by the rich voter with future transfers. Thus, for a tacit lobbying agreement to emerge it is necessary that both candidates are conditional cooperators. Moreover, to earn strictly more than $\bar{e}$, the rich voter's expected tax favor must

\footnotetext{
10 Axelrod's (1981) tit-for-tat player is a prominent example of conditional cooperation in repeated prisoners' dilemma games, but generally, conditional responses to the (expected) behavior of others can be adapted to the specific decision-making situation. One could also introduce other types of players (e.g., altruist or competitive types). However, we focus on self interest and conditional cooperation since they describe the behavior of the majority of people in games that involve cooperation (see Fischbacher, Gächter, and Fehr 2001).

11 Note that complete information about the types of all players is the limit case of incomplete information where everyone has correct beliefs about the others' types.
} 
exceed her total transfers, $\left(1-E\left[t_{w}\right]\right)\left(e_{R}-\bar{e}\right)>l_{R}$, irrespective of her type. Finally, in expectation a candidate must earn strictly more than $\omega+\frac{b}{2}$. In other words, if she chooses a tax policy strictly smaller than 1 during the policymaking process, she must expect total costs of policy changes that are strictly smaller than her received transfers.

We continue by examining the emergence of tacit agreements in the finitely-repeated lobbying game. To do so, we use the reasoning of Kreps et al. (1982), who analyze a finitelyrepeated prisoners' dilemma where players can be either self-interested or conditionallycooperative and there is incomplete information regarding the other player's type. They show that, even if the probability of meeting a conditional cooperator is small, sequential equilibria exist where both players cooperate for some repetitions of the game (but there is also always a sequential equilibrium with mutual defection in every period). Although cooperation in the lobbying game is more complex than in the prisoners' dilemma, their reasoning also applies in our context. Importantly, in the finitely-repeated lobbying game the set of feasible sequential equilibria involving tacit lobbying agreements is markedly larger than in the one-shot version of the game. This is because, depending on their expected continuation profits for remaining in the coalition, self-interested candidates now have an incentive to mimic conditional cooperators for some periods of the game (cf. Prediction 2 where agreements cannot arise if there is at least one self-interested candidate). For the simple reason that more candidates have an incentive to cooperate — which also increases everyone's belief of collusion being successful—we expect more tacit lobbying agreements to emerge in repeated than in one-shot encounters. Our arguments based on sequential equilibrium are summarized as follows:

Prediction 3 (Tacit lobbying agreements with finitely-repeated encounters): In the finitelyrepeated lobbying game with incomplete information about the other players' types-who are either self-interested or conditionally-cooperative-tacit lobbying agreements can arise in periods where the rich voter and both candidates expect positive continuation profits from colluding. Otherwise, we predict zero transfers and full redistribution (as in Prediction 1). Moreover, tacit lobbying agreements are more likely in repeated than in one-shot encounters, but this difference declines over time as expected continuation profits decrease. 
Argument: This prediction follows from the discussion above.

Predictions 2 and 3 describe a large set of tacit lobbying agreements. However, it is doubtful that all agreements receive (equal) support from potential colluders. In order to refine our predictions and select agreements that are more plausible than others, we turn to profit-sharing norms derived from the equity principle (Adams 1965; Selten 1978). ${ }^{12}$ Such "equity norms" can serve as focal points for how to divide joint profits (Schelling 1960) and have lots of empirical support (see Konow 2003). Since corporate firms usually have much larger incomes than political candidates-meaning that dividing the surplus from collusion is more realistic than dividing the coalition's total payoff-and candidates are symmetric in our setup, a suitable equity norm to analyze tacit lobbying agreements is split-the-difference. This norm has been found to be very important for individuals in bargaining situations (see Konow 2003). In our context, split-the-difference proposes that the joint profits from a tacit lobbying agreement (i.e., the amount not redistributed to the majority, $\left(1-t_{w}\right)\left(e_{R}-\bar{e}\right)$ ) are to be divided equally among the three colluders. ${ }^{13}$

Following the arguments given above, we predict that the tacit lobbying agreements that do materialize are likely to be consistent with the split-the-difference norm. However, there is an important caveat due to the sequencing of transfer and tax policy decisions, which puts the rich voter in the weaker "trustor" position compared to the candidates' stronger "trustee" position. To be precise, the rich voter can have negative returns from her investments (i.e., earn less than 40 points) if at least one candidate returns no or insufficient tax favors. In contrast, candidates can always guarantee themselves the expected 35 points in the benchmark. This asymmetry may favor the candidates, in which case agreements where the candidates capture most of the joint profits and the rich voter just breaks even would be more likely.

\footnotetext{
12 The equity principle requires a relationship between an individual's input (e.g., a contribution) and her output (e.g., a share of the profit) that applies equally to all individuals in a reference group. It is considered one of the most important principles in theories of justice (Konow 2003).

13 Another prominent norm is the equal split, which divides equally the total payoff of all individuals in the reference group. With our experimental parameters, both norms predict very similar tacit lobbying agreements.
} 
Prediction 4 (Profit-sharing): Deviations from zero transfers and full redistribution where the rich voter's investment breaks even and tacit lobbying agreements where the rich voter and the two candidates "split-the-difference" are most common.

\section{Procedures and experimental design}

The computer experiment was run in the laboratory of the Kellogg School of Management of Northwestern University in 2008. A total of 217 students participated in 20 sessions of eight to twelve subjects. Each session lasted one hour. At the end of a session, earnings were paid in cash at a rate of 50 points to one US dollar. Subjects earned an average of $\$ 21.27$. The experiment was programmed with z-Tree (Fischbacher 2007). A sample of instructions used in the experiment is provided in our online appendix.

We employed a $2 \times 2$ treatment design. On one dimension, we varied the length of subject interaction between random matching (Strangers) and fixed matching (Partners). On the other dimension, we varied between the lobbying (Lobbying) and redistribution games (No-Lobbying). This gives our four treatments: Strangers-No Lobbying, StrangersLobbying, Partners-No Lobbying, and Partners-Lobbying. Each treatment used 15 decision periods and parameters as previously described (subjects had all this information). Moreover, at the beginning of the respective stage, everyone in the society was informed of: the amount the rich voter transferred to each candidate, the pair of tax policies accepted by the candidates (although, only candidates observe the entire policymaking process), and the number of votes obtained by each candidate in the election.

In Strangers, at the beginning of a session four subjects were randomly assigned to be voters and all others were put into a candidate pool of four to eight (the number of candidates depended on the number of subjects that showed up). The assignment of voters and candidates never changed during the entire session. At the beginning of each period, the voters were randomly divided into one rich voter and three poor voters. Similarly, the candidates were randomly divided into two active candidates, labeled $A$ or $B$, and two to six inactive candidates. Only the active candidates in a period could make decisions; their inactive counterparts received 25 points and could watch the game on their screens. Since 
Table 1 - Summary of experimental design

\begin{tabular}{ccccc}
\hline \hline & \multicolumn{3}{c}{ Lobbying opportunities-within subjects- } \\
& $\begin{array}{c}\text { No Lobbying } \rightarrow \\
\text { Lobbying }\end{array}$ & $\begin{array}{c}\text { Lobbying } \rightarrow \\
\text { No Lobbying }\end{array}$ & Total \\
\hline Matching & Strangers & $5(49)$ & $6(66)$ & $11(115)$ \\
- between subjects- & Partners & $8(48)$ & $9(54)$ & $17(102)$ \\
\hline \hline
\end{tabular}

Notes: The table shows the number of independent societies (and the number of subjects in parenthesis) used per matching protocol (Strangers or Partners). These numbers are also shown separately by the sequence in which the lobbying (Lobbying) and redistribution games (No Lobbying) were played.

the constant reassignment of roles among voters and roles and labels among candidates made it practically impossible for an individual to build up reputation, our Strangers treatments resemble 15 successive one-shot games.

In Partners, at the beginning of a session subjects were randomly assigned to statistically independent societies of six subjects. Thereafter, each society was randomly divided into one rich voter, three poor voters, and two candidates $A$ or $B$ (there were no inactive candidates). Unlike in Strangers, the voters' roles and the candidates' labels never changed during the entire session. Therefore, our Partners treatments represent finitelyrepeated games.

We varied Lobbying and No Lobbying within subjects and Strangers and Partners between subjects. Specifically, each session contained two parts (i.e., treatments) of 15 periods. Subjects knew there would be two parts, but they received the instructions of the second part only after the first part was completed. To account for order effects, some sessions began with Lobbying and continued with No Lobbying and vice versa in the other sessions. Table 1 summarizes the experimental design and specifies the number of societies (i.e., independent observations) and subjects in each treatment and sequence. 
Table 2 - Summary statistics

\begin{tabular}{cccccccc}
\hline \hline & All tax policies & \multicolumn{3}{c}{ Winning tax policies } & Transfers & Voting \\
\cline { 2 - 7 } & Mean & $\begin{array}{c}\text { Mean prop. } \\
\text { equal to 1 }\end{array}$ & Mean & $\begin{array}{c}\text { Mean prop. } \\
\text { equal to 1 }\end{array}$ & Mean & $\begin{array}{c}\text { Mean prop. } \\
\text { equal to 0 }\end{array}$ & $\begin{array}{c}\text { Prop. } \\
\text { unexpected } \\
\text { outcomes }\end{array}$ \\
\hline Strangers- & 0.957 & 0.845 & 0.979 & 0.921 & - & - & 0.006 \\
No Lobbying & $(0.140)$ & $(0.362)$ & $(0.082)$ & $(0.270)$ & & & $(0.078)$ \\
Strangers- & 0.926 & 0.824 & 0.976 & 0.897 & 8.055 & 0.648 & 0.030 \\
Lobbying & $(0.207)$ & $(0.381)$ & $(0.084)$ & $(0.304)$ & $(18.356)$ & $(0.478)$ & $(0.172)$ \\
Partners- & 0.949 & 0.880 & 0.974 & 0.945 & - & - & 0.008 \\
No Lobbying & $(0.173)$ & $(0.325)$ & $(0.127)$ & $(0.228)$ & -184 & 0.590 & 0.020 \\
Partners- & 0.818 & 0.655 & 0.863 & 0.725 & 6.184 & $0.088)$ \\
Lobbying & $(0.315)$ & $(0.476)$ & $(0.273)$ & $(0.447)$ & $(9.512)$ & $(0.492)$ & $(0.139)$ \\
\hline \hline
\end{tabular}

Notes: Table reports means. Standard deviations are in parenthesis.

\section{Experimental results}

In this section, we present our experimental results. First, we describe the election outcomes. Thereafter, we analyze the observed tax policies and their relationship with transfers. Lastly, we discuss the payoff consequences of lobbying.

Table 2 contains summary statistics for the main variables in the experiment (standard deviations are given in parenthesis). For each treatment, it displays the means for: tax policies, the proportion of tax policies equal to 1, winning tax policies, the proportion of winning tax policies equal to 1 , transfers, the proportion of transfers equal to 0 , and the proportion of election outcomes that are 'unexpected' (i.e., where the candidate with a lower tax wins, which cannot be explained by everyone voting sincerely according to own pecuniary interests).

\section{Elections}

As seen in the last column of Table 2, only between $0.6 \%$ and $3.0 \%$ of all elections result in an unexpected outcome. In part, this is due to a majority of elections pitting two candidates with identical tax policies, as observed in $78.2 \%$ (75.2\%; 83.5\%; 63.5\%) of all elections in Strangers-No Lobbying (Strangers-Lobbying; Partners-No Lobbying; Partners-Lobbying). However, in elections with different tax policies the higher-tax candidate does indeed 

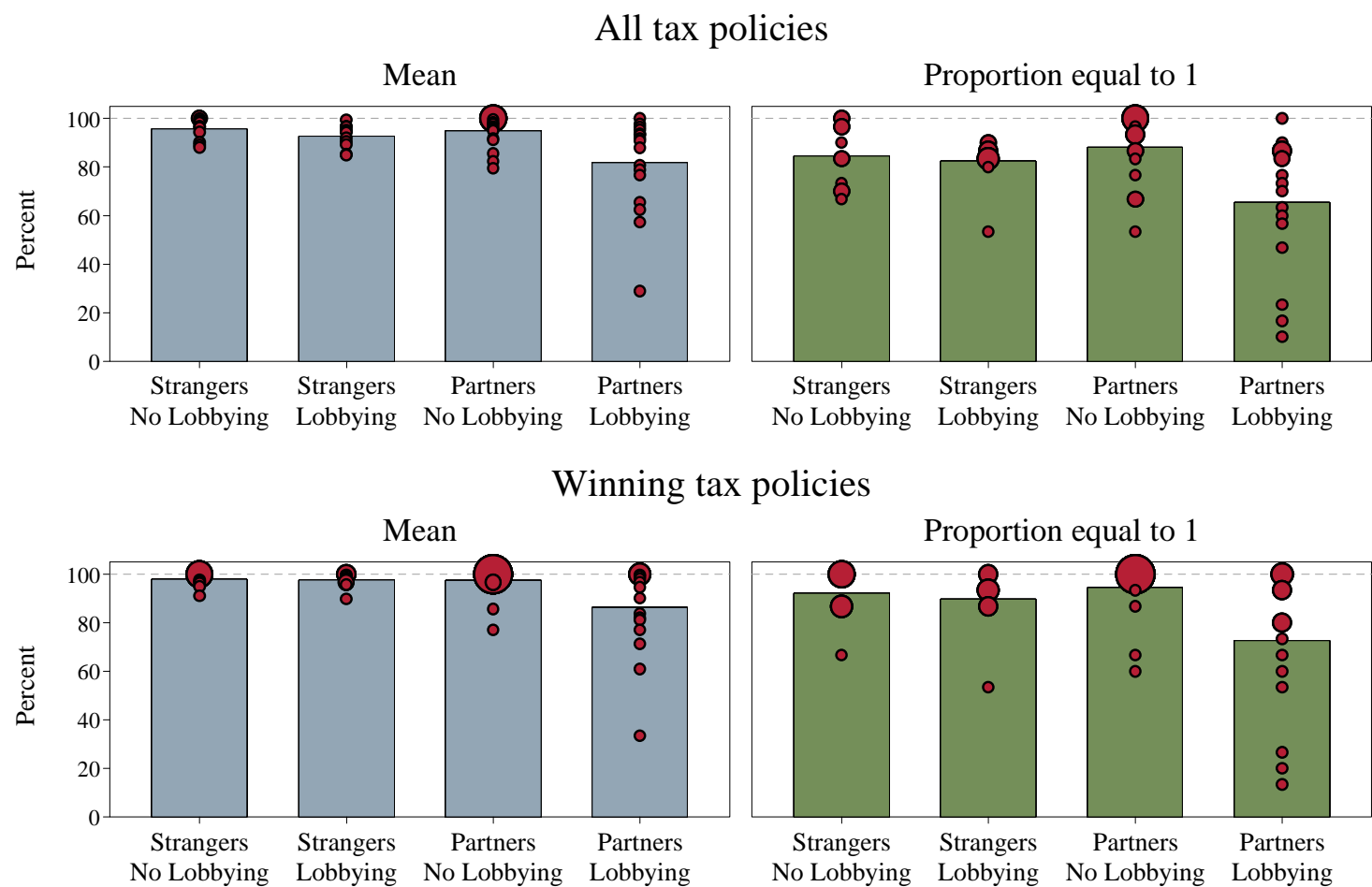

Figure 1 - Tax policies per treatment and society

Notes: The two top panels show the mean tax policy (left) and the mean proportion of tax policies equal to 1 (right) for each treatment. Within each panel, the bars (circles) depict the statistic calculated per treatment (per society; larger circles indicate more than one society). Similarly, the two bottom panels show the mean winning tax policy (left) and the mean proportion of winning tax policies equal to 1 (right).

overwhelmingly win: $98.4 \%(88.0 \% ; 97.5 \% ; 95.3 \%)$ of the time. This happens because voting is mostly sincere, i.e., the rich voter votes for the lower-tax candidate and the three poor voters for the higher-tax candidate. ${ }^{14}$ We have arrived at our first experimental result:

Experimental Result 1 (Election outcomes): In most elections, candidates choose identical tax policies. In elections where voters face two different tax policies, the candidate with the higher tax almost always wins.

14 In elections with different tax policies we observe on average sincere votes between 93.6\% (StrangersLobbying) and 97.9\% (Strangers-No Lobbying) of the time. 
For convenience, since unexpected election outcomes are so rare and our focus is on tacit lobbying agreements, we henceforth treat these elections "as if" they are consistent with the majority's pecuniary interest.

\section{Tax policies}

Figure 1 shows for the various treatments the mean tax policy and the mean proportion of tax policies equal to 1. It portrays the means for each treatment as bars and for each society as circles. Moreover, we distinguished between statistics for both candidates' tax policies (upper panels) and for winning tax policies only (lower panels). The figure clearly illustrates that in Strangers-No Lobbying, Strangers-Lobbying, and Partners-No Lobbying mean (winning) tax policies are very close to 100\%: they lie between $92.6 \%$ and $95.7 \%$ (97.4\% and 97.9\%). Moreover, there is very little variation in mean (winning) tax policies across societies. In Partners-Lobbying, we observe that the mean (winning) tax policy is unmistakably lower: it equals $81.8 \%(86.3 \%)$. What is more, we also see considerable variation across societies (e.g., mean winning tax policies ranged from $100.0 \%$ to $33.3 \%$ ). The same pattern is observed for the mean proportion of (winning) tax policies equal to 1 , but understandably, these means are slightly lower (see Table 2).

To test whether tax policies are significantly different across treatments, we estimate a Tobit regression with the tax policy as the dependent variable (censored at 1) and treatment dummies as independent variables. We use a nested model with subject and society random effects, and robust standard errors clustered at the society level. ${ }^{15}$ This method allows us to fully utilize the panel structure of our data and take into account that the distribution of tax policies is censored. Throughout the paper, unless it is otherwise noted, all reported $p$-values are based on two-tailed tests. The statistical tests confirm our initial impression. There are no significant differences in tax policies or winning tax policies between Strangers-No Lobbying, Strangers-Lobbying, and Partners-No Lobbying (for all comparisons, $p>0.162$ and $p>0.205$, respectively). In contrast, we find that tax policies

\footnotetext{
15 We estimate the regressions using the generalized linear latent and mixed models program (GLLAMM) described by Rabe-Hesketh et al. (2005).
} 
and winning tax policies are significantly lower in Partners-Lobbying compared to each of the other treatments (for all comparisons, $p \leq 0.005$ and $p \leq 0.034$, respectively). ${ }^{16}$ Finally, Conover's (1980) squared-rank tests for equality of variances rejects the null hypothesis of no differences in favor of more variation in tax policies and winning tax policies in PartnersLobbying compared to each of the other treatments $(p \leq 0.001)$. We have arrived at our second experimental result (which we will compare to our predictions after presenting the third experimental result):

Experimental Result 2 (Tax policies): Clear deviations from full redistribution occur only in the presence of both repeated interaction and the opportunity to lobby. Moreover, there is considerable heterogeneity in the magnitude of these deviations across societies.

\section{Tacit lobbying agreements and mutual reciprocation}

In this subsection, we examine in more detail the conditions under which lobbying can stimulate low tax policies. Table 2 shows that the lobbying success in this treatment is not due to different amounts transferred to the candidates. In an average period, rich voters send 8.055 points per candidate in Strangers and 6.184 points in Partners. A Tobit regression with the mean transfer per candidate as the dependent variable (censored at 0 points) and the same characteristics as our previous regressions cannot reject the null hypothesis of no differences in transfers between Strangers and Partners $(p=0.832) .{ }^{17}$ This raises the question, why can lobbying be successful only with repeated interaction?

\footnotetext{
16 We obtain very similar results using nonparametric tests with society means as the unit observations. We use Fligner-Policello robust-rank-order tests for between-subject comparisons and Wilcoxon signed-rank tests for within-subject comparisons. Tax policies and winning tax policies are lower in Partners-Lobbying compared to each of the other treatments (one-tailed tests, $p \leq 0.056$ and $p \leq 0.053$ ). There are no significant differences in tax policies and winning tax policies between Strangers-No Lobbying, Strangers-Lobbying, and Partners-No Lobbying (one-tailed tests, $p>0.240$ ), with one exception: tax policies (but not winning tax policies) are significantly lower in Strangers-No Lobbying than Strangers-Lobbying (one-tailed test, $p=0.023$ ).

17 There are also no significant differences with a Fligner-Policello robust-rank-order test with society means as the unit observations (one-tailed test, $p=0.241$ ).
} 
Figure 2 depicts in more detail the relationship between transfers and tax policies for both Strangers-Lobbying and Partners-Lobbying. It contains scatter plots with the mean transfers per candidate on the horizontal axis and the mean (winning) tax policy in percent on the vertical axis. Each data point represents one society. We can easily interpret the figure starting from the benchmark given by Prediction 1 (the top-left corner of each scatter plot) where each voter earns 40 points and each candidate earns an average of 35 points. From here, the rich voter's payoff strictly decreases as transfers increase or as the winning tax policy increases. The candidates' average payoff strictly increases with transfers and does not directly depend on the tax policy. Finally, the poor voters' average payoff strictly increases with the winning tax policy and does not directly depend on transfers. In addition, Figure 2 shows the break-even line (black line), which contains all pairs of mean transfers and winning tax policies where the rich voter earns 40 points, i.e., her total transfers equal the benefits from lower tax policies. Therefore, since the rich voter earns less than 40 points in the white area above the break-even line and more than 40 points in the gray area below it, the gray-shaded area corresponds to the set of symmetric tacit lobbying agreements (i.e., with equal transfers per candidate and equal tax policies). ${ }^{18}$ The split-the-difference line (gray line) contains all pairs of symmetric transfers and tax policies where the rich voter and each candidate receive an equal share of the points not redistributed to the poor voters. Lastly, the figure also shows best-fit lines that plot the estimated relationship between mean transfers and tax policies using a Tobit regression (censored at 1 and with robust standard errors).

In Strangers, all the eleven societies have a mean winning tax policy close to $100 \%$ (with perhaps one exception at 89.7\%). The mean transfers per candidate, on the other hand, differ across societies: five societies have low levels (less than 5 points), four have moderate levels (around 10 points), and two have very high levels (around 20 points). What is clearly seen in Figure 2 is that there is no relationship between mean transfers and mean

\footnotetext{
18 There are also tacit lobbying agreements with asymmetric transfers and tax policies. These include special cases of split-the-difference where one candidate chooses a lower tax policy than the other and loses the election but is compensated for doing so with a larger transfer from the rich voter.
} 


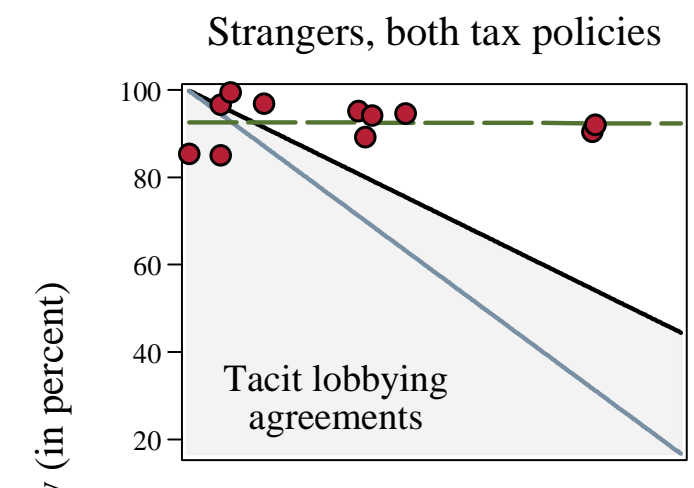

Strangers, winning tax policy
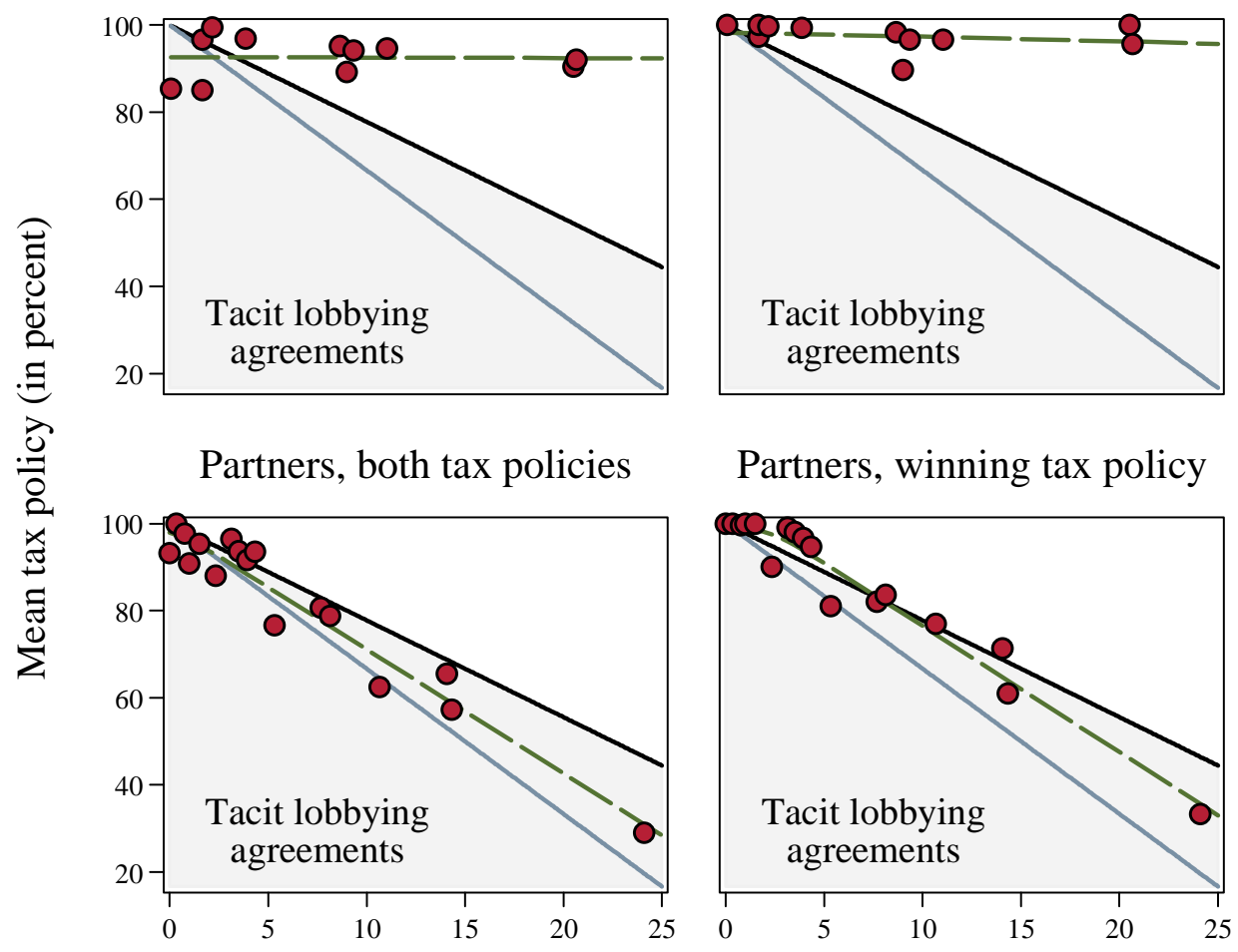

Partners, winning tax policy

Mean transfer per candidate (in points)

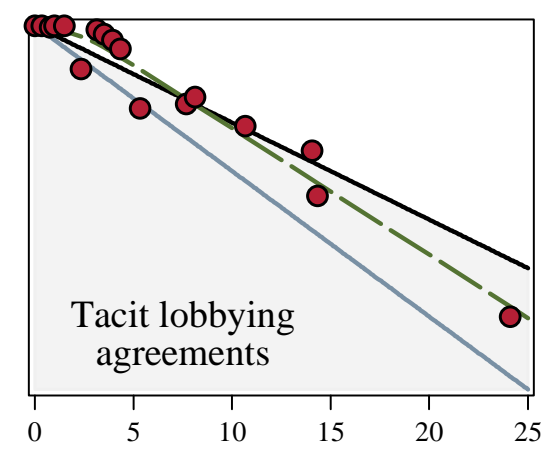

\section{Break-even \\ Split-the-difference \\ Best fit}

Figure 2 - Transfers and tax policies

Notes: The figure shows the mean transfer per candidate on the horizontal axis and the mean (winning) tax policy on the vertical axis for each society (circles) in Strangers-Lobbying and Partners-Lobbying. Each panel also shows the break-even line (black), the split-the-difference line (blue), the estimated relationship or best fit between mean transfers and tax policies using a Tobit regression (green dashed line), and the set of symmetric tacit lobbying agreements (gray shaded area).

(winning) tax policies in this treatment. Tobit regressions (the best fit lines) using mean transfers to predict tax policies and winning tax policies yield statistically insignificant coefficients of $-0.010(p=0.961)$ and $-0.136(p=0.453)$.

In Partners we can distinguish two sets of societies: high-tax and low-tax societies. There are ten high-tax societies where, apparently, little effort was made towards reaching tacit lobbying agreements. Namely, on average, they have low transfers per candidate (less than 5 points) and high winning tax policies (between $90 \%$ and 100\%). On the other hand, 
there are seven low-tax societies with higher transfers per candidate (more than 5 points) and low winning tax policies (between 33.3\% and 83.7\%). Consequently, in Partners we see a clear negative relationship between transfers and tax policies (see Figure 2). Interestingly, these data points are well organized by the area in-between the break-even and split-thedifference lines, supporting our Prediction 4. Specifically, Tobit regressions (the best fit lines) using mean transfers to predict tax policies and winning tax policies yield statistically significant coefficients of $-2.850(p \leq 0.001)$ and $-2.900(p \leq 0.001)$. For comparison, the coefficients for the mean transfer implied by the break-even and split-the-difference lines are -2.222 and -3.333 , respectively. We can summarize our findings as: ${ }^{19}$

Experimental Result 3 (Tacit lobbying agreements): Tacit lobbying agreements among the rich voter and the two candidates arise in $41.2 \%$ of societies with repeated interaction. In these societies, rich voters make substantial lobbying transfers and the candidates reciprocate by lowering their tax policies in proportion to the amounts received.

We can compare Experimental Results 2 and 3 to our theoretical predictions. By and large, the results in Strangers-No Lobbying and Partners-No Lobbying are in line with Prediction 1. We do not observe tacit lobbying agreements in Strangers-Lobbying, which is consistent with Prediction 1 and the second part of Prediction 2 (but not with the first part of Prediction 2). However, since there are some unsuccessful lobbying attempts, the second part of Prediction 2 appears to be more reasonable than Prediction 1 (i.e., subjects believe conditional cooperators exist but are not enough to support cooperation in a one-shot lobbying game). Finally, Prediction 3 is supported in Partners-Lobbying: tacit lobbying agreements emerge, and they do so more often than in Strangers-Lobbying (41.2\% vs. 0\%).

\footnotetext{
${ }^{19}$ In Figure 2, three low-tax societies in Partners-Lobbying lie just below the break-even line. According to our definition of tacit lobbying agreements, all colluders must be strictly better off than in Prediction 1 . While this does not hold on average in these societies, it does for most periods and it only breaks down in later periods due to endgame effects (see Prediction 3). For ease of illustration, we do not distinguish between low-tax societies and treat them all as societies where tacit lobbying agreements arise (in most of the periods).
} 
Are tacit lobbying agreements the result of mutual reciprocation between the rich voter and the two candidates? To answer this question, we use regression analysis to test whether changes in transfers can predict subsequent changes in tax policies and vice versa. Here, we only analyze the Partners-Lobbying treatment since it is where a positive correlation between transfers and tax policies exists (results for Strangers-Lobbying are available in our online appendix). We first investigate the effects of changes in transfers on tax policies before we examine the reverse effects.

Table 3 presents the results of OLS regressions using as the dependent variable the change in candidate $j$ 's tax policy (in percentage-points) from the previous period $x-1$ to the current period $x:\left(t_{j, x}-t_{j, x-1}\right) \times 100$. Our first independent variable measures the change in the number of points transferred to candidate $j$ from $x-1$ to $x: l_{R \rightarrow j, x}-l_{R \rightarrow j, x-1}$, and our second independent variable interacts the first one with the current period: $\left(l_{R \rightarrow j, x}-l_{R \rightarrow j, x-1}\right) \times x$. These two variables allow us to test whether candidates reciprocate the rich voter's behavior and whether reciprocation diminishes as the end of the game nears. The next two independent variables measure positive and negative differences between the tax policy of candidate $j$ and the tax policy of candidate $-j$ in the previous period: $\max \left[\left(t_{j, x-1}-t_{-j, x-1}\right) \times 100,0\right]$ and $\max \left[\left(t_{-j, x-1}-t_{j, x-1}\right) \times 100,0\right]$, respectively. These two variables capture the candidates' reaction to the actions of the other candidate across periods. Finally, we use $x$ as an independent variable to measure a potential time trend. The regressions are run with subject fixed effects to control for unobservable characteristics and with robust standard errors clustered at the society level.

The first regression in Table 3 is run with all societies in Partners-Lobbying. As we can see, candidates respond negatively to changes in lobbying transfers (the coefficient of $l_{R \rightarrow j, x}-l_{R \rightarrow j, x-1}$ is statistically significant; $p=0.009$ ). Thus, candidates do reciprocate by decreasing (increasing) their tax policies in proportion to a previous increase (decrease) in received transfers. Moreover, the coefficient of $\left(l_{R \rightarrow j, x}-l_{R \rightarrow j, x-1}\right) \times x$ is positive, indicating that the candidates' propensity to reciprocate declines over time $(p=0.052)$. These two findings are consistent with Prediction 3. The coefficient for $\max \left[\left(t_{-j, x-1}-t_{j, x-1}\right) \times 100,0\right]$ indicates that if candidate $j$ chose a lower tax policy than candidate $-j$ in the previous 
Table 3 - Candidates: determinants of tax policy changes in Partners-Lobbying

\begin{tabular}{cccc}
\hline \hline $\begin{array}{c}\text { Independent variables } \\
\text { and constant }\end{array}$ & $\begin{array}{c}\text { All } \\
\text { societies }\end{array}$ & $\begin{array}{c}\text { High-tax } \\
\text { societies }\end{array}$ & $\begin{array}{c}\text { Low-tax } \\
\text { societies }\end{array}$ \\
\hline Change in own transfer & $-0.876^{* * *}$ & $-0.604^{* * *}$ & $-1.102^{* * *}$ \\
$l_{R \rightarrow j, x}-l_{R \rightarrow j, x-1}$ & $(0.297)$ & $(0.194)$ & $(0.333)$ \\
Change in own transfer $\times$ period & $0.093^{*}$ & $0.053^{* *}$ & $0.118^{* *}$ \\
$\left(l_{R \rightarrow j, x}-l_{R \rightarrow j, x-1}\right) \times x$ & $(0.044)$ & $(0.019)$ & $(0.049)$ \\
Positive diff. in previous tax policies & -0.201 & 0.022 & $-0.448^{* *}$ \\
max $\left[\left(t_{j, x-1}-t_{-j, x-1}\right) \times 100,0\right]$ & $(0.129)$ & $(0.017)$ & $(0.189)$ \\
Negative diff. in previous tax policies & $0.777^{* * *}$ & $0.807^{* * *}$ & $0.709^{* * *}$ \\
max $\left[\left(t_{-j, x-1}-t_{j, x-1}\right) \times 100,0\right]$ & $(0.101)$ & $(0.144)$ & $(0.141)$ \\
Period & -0.034 & -0.377 & 0.574 \\
$x$ & $(0.307)$ & $(0.378)$ & $(0.442)$ \\
Constant & -1.003 & 0.692 & -3.715 \\
& $(2.801)$ & $(3.278)$ & $(4.104)$ \\
\hline Number of observations & 476 & 280 & 196 \\
Number of subjects & 34 & 20 & 14 \\
Number of societies & 17 & 10 & 7 \\
$R^{2}$ & 0.192 & 0.323 & 0.168 \\
\hline \hline
\end{tabular}

Notes: OLS regressions with changes in candidate $j$ 's tax policy from period $x-1$ to period $x$ as the dependent variable: $\left(t_{j, x}-t_{j, x-1}\right) \times 100$. Robust standard errors are given in parenthesis. ${ }^{*},{ }^{* *}$, and ${ }^{* * *}$ indicate statistical significance at the $10 \%, 5 \%$, and $1 \%$ level.

period—recall that lower taxes are almost always defeated—she responds by significantly increasing her current tax policy $(p \leq 0.001)$. The response to positive differences in tax policies is much smaller and insignificant.

To examine whether these findings are crucial determinants for tacit lobbying agreements to arise, we ran the same OLS regressions separating the ten high-tax societies (third column in Table 3) from the seven low-tax societies (fourth column). In both cases, we observe the same pattern of candidate reciprocity: a significant negative relationship between changes in transfers and tax policies $(p \leq 0.007)$ and a significant decline over time of the candidates' propensity to reciprocate $(p \leq 0.029)$. As one might suspect, reciprocation is stronger in low-tax than in high-tax societies, but the difference between the coefficients 
is not statistically significant $(p=0.215) .^{20}$ In fact, the only variable with significant differences between both regressions is $\max \left[\left(t_{j, x-1}-t_{-j, x-1}\right) \times 100,0\right](p=0.025)$. This result gives us an important insight of why tacit lobbying agreements emerge in some societies and not in others. In high-tax societies, if candidate $-j$ 's tax policy was lower than candidate $j$ 's in the previous period, candidate $j$ does not significantly change her tax policy in the current period ( $p=0.218$ ). In contrast, in low-tax societies, candidate $j$ responds to the same situation by significantly lowering her tax policy $(p=0.031)$. Thus, it seems that a necessary determinant for tacit lobbying agreements to emerge is that candidates reciprocate a (defeated) lower tax policy of the other candidate by decreasing their own tax policy in the next period.

Next, we look at the other side of the coin of mutual reciprocation. Do rich voters reward lower tax policies with higher transfers and punish higher tax policies with lower transfers? Behaviorally, reciprocation is slightly more complicated for rich voters than for candidates because, as first movers, they cannot reciprocate within the same period. This implies that they must evaluate the actions of candidates in the previous period taking into account that candidates were reacting to their own previous action. Table 4 presents the results of OLS using as the dependent variable the change in the rich voters' total transfers from period $x-1$ to period $x: l_{R, x}-l_{R, x-1}$. For our independent variables, we distinguish between two situations: periods following an increase in total transfers and periods following no such increase. This distinction proxies the rich voter's normative expectations of the candidates' behavior. Specifically, we assume that rich voters think candidates should lower their taxes after an increase in transfers but have no such presumption otherwise. Our first two independent variables measure changes in the winning tax policy after a previous increase in the rich voter's total transfers: $\left(t_{w, x-1}-t_{w, x-2}\right) \times 100$ if $l_{R, x-1}>l_{R, x-2}$ (zero otherwise), or after no previous increase: $\left(t_{w, x-1}-t_{w, x-2}\right) \times 100$ if $l_{R, x-1} \leq l_{R, x-2}$ (zero otherwise). Moreover, we interact both variables with the current period, $\left(t_{w, x-1}-t_{w, x-2}\right) \times 100 \times x \quad$ if $\quad l_{R, x-1}>l_{R, x-2} \quad$ and $\quad\left(t_{w, x-1}-t_{w, x-2}\right) \times 100 \times x \quad$ if

20 Differences between the coefficients of high-tax and low-tax societies are tested with one regression where we interact all the independent variables with dummy variables indicating whether a society is a high-tax society. 
$l_{R, x-1} \leq l_{R, x-2}$, which gives two more independent variables. We are also interested in testing whether rich voters reciprocate (unilateral) changes in tax policies that do not affect the winning tax policy. To test this, we compute the difference between winning $(w)$ and losing $(-w)$ tax policies, $\Delta t_{x-1} \equiv\left(t_{w, x-1}-t_{-w, x-1}\right) \times 100$, and use it for two independent variables: $\Delta t_{x-1}-\Delta t_{x-2}$ if $l_{R, x-1}>l_{R, x-2}$ (zero otherwise) and $\Delta t_{x-1}-\Delta t_{x-2}$ if $l_{R, x-1} \leq l_{R, x-2}$ (zero otherwise). Finally, we use a dummy variable equal to 1 in periods following an increase in total transfers: 1 if $l_{R, x-1}>l_{R, x-2}$ (zero otherwise), and the current period $x$ to measure a potential time trend. The regressions are run with subject fixed effects and robust standard errors clustered at the society level.

The first regression in Table 4 is run with all societies in Partners-Lobbying. We find strong support for reciprocation by rich voters. To see this, let's start with the case in which they previously increased their total transfer but tax policies do not change. Given our independent variables, this case is captured by the coefficient of the dummy variable 1 if $l_{R, x-1}>l_{R, x-2}$. As we can see, in this case, rich voters punish by significantly decreasing transfers $(p \leq 0.001)$. Compared to this baseline, if candidates manage to decrease the winning tax policy, rich voters reward candidates by increasing their transfer (the coefficient of $\left(t_{w, x-1}-t_{w, x-2}\right) \times 100$ if $l_{R, x-1}>l_{R, x-2}$ is significantly negative; $\left.p=0.007\right) .{ }^{21}$ Moreover, the positive coefficient of $\left(t_{w, x-1}-t_{w, x-2}\right) \times 100 \times x$ if $l_{R, x-1}>l_{R, x-2}$ is consistent with a declining propensity to positively reciprocate over time, albeit the coefficient is not statistically significant $(p=0.153)$. In contrast, we find that rich voters do not significantly reciprocate decreases in winning tax policies if they are not the consequence of a previous increase in their transfers (coefficient of $\left(t_{w, x-1}-t_{w, x-2}\right) \times 100$ if $l_{R, x-1} \leq l_{R, x-2} ; p=0.398$ ) or decreases in losing tax policies that do not affect the winning tax policy (coefficients of the two variables for $\Delta t_{x-1}-\Delta t_{x-2} ; p>0.364$ ).

\footnotetext{
21 This coefficient is mostly identifying rewards by the rich voters since there are few cases in which an increase in transfers (i.e., $l_{R, x-1}>l_{R, x-2}$ ) is followed by an increase in the winning tax policy (i.e., $\left(t_{w, x-1}-t_{w, x-2}\right) \times$ $100>0$ ). Note that transfers increase in absolute terms depending on the magnitude of the change in the winning tax policy, which must decrease by at least 0.258 .
} 
Table 4 - Rich voters: determinants of transfer changes in Partners-Lobbying

\begin{tabular}{cccc}
\hline Independent variables and constant & $\begin{array}{c}\text { All } \\
\text { societies }\end{array}$ & $\begin{array}{c}\text { High-tax } \\
\text { societies }\end{array}$ & $\begin{array}{c}\text { Low-tax } \\
\text { societies }\end{array}$ \\
\hline Change in winning tax after transfers increase & $-0.617^{* * *}$ & $-0.816^{* *}$ & $-0.596^{* *}$ \\
$\left(t_{w, x-1}-t_{w, x-2}\right) \times 100$ if $l_{R, x-1}>l_{R, x-2}$ & $(0.202)$ & $(0.320)$ & $(0.256)$ \\
Change in winning tax after transfers increase $\times$ period & 0.041 & $0.124^{* *}$ & 0.036 \\
$\left(t_{w, x-1}-t_{w, x-2}\right) \times 100 \times x$ if $l_{R, x-1}>l_{R, x-2}$ & $(0.027)$ & $(0.049)$ & $(0.033)$ \\
Change in winning tax after no transfers increase & -0.156 & 0.728 & -0.235 \\
$\left(t_{w, x-1}-t_{w, x-2}\right) \times 100$ if $l_{R, x-1} \leq l_{R, x-2}$ & $(0.179)$ & $(1.409)$ & $(0.155)$ \\
Change in winning tax after no transfers increase $\times$ period & 0.005 & -0.118 & 0.011 \\
$\left(t_{w, x-1}-t_{w, x-2}\right) \times 100 \times x$ if $l_{R, x-1} \leq l_{R, x-2}$ & $(0.016)$ & $(0.156)$ & $(0.013)$ \\
Change in the diff. in taxes after transfers increase & 0.070 & 0.039 & 0.075 \\
$\Delta t_{x-1}-\Delta t_{x-2}$ if $l_{R, x-1}>l_{R, x-2}$ & $(0.074)$ & $(0.155)$ & $(0.083)$ \\
Change in the diff. in taxes after no transfers increase & 0.015 & -0.029 & $0.080^{* *}$ \\
$\Delta t_{x-1}-\Delta t_{x-2}$ if $l_{R, x-1} \leq l_{R, x-2}$ & $(0.031)$ & $(0.026)$ & $(0.034)$ \\
Increased transfers & $-15.925^{* * *}$ & $-19.980^{* * *}$ & $-12.980^{* * *}$ \\
1 if $l_{R, x-1}>l_{R, x-2}$ & $(3.219)$ & $(5.024)$ & $(3.729)$ \\
Period & -0.345 & -0.412 & -0.176 \\
$x$ & $(0.216)$ & $(0.391)$ & $(0.335)$ \\
Constant & $7.138^{* *}$ & 6.052 & 7.305 \\
Number of subjects $/$ societies & $(2.650)$ & $(4.517)$ & $(4.550)$ \\
\hline \hline Number of observations & 221 & 130 & 91 \\
\hline \hline
\end{tabular}

Notes: OLS regressions with changes in the rich voters' total transfers from period $x-1$ to period $x$ as the dependent variable, $l_{R, x}-l_{R, x-1}$. Robust standard errors are in parenthesis. ${ }^{* *}$ and ${ }^{* * *}$ indicate statistical significance at the $5 \%$ and $1 \%$ level.

We distinguish between OLS regressions for the eleven high-tax societies and seven low-tax societies next (see last two columns in Table 4). By and large, we find very similar results. In both regressions, rich voters punish candidates that do not respond to increases in transfers (coefficients of 1 if $l_{R, x-1}>l_{R, x-2} ; p \leq 0.003$ ) and reward lower winning tax policies with higher transfers (coefficients of $\left(t_{w, x-1}-t_{w, x-2}\right) \times 100$ if $l_{R, x-1}>l_{R, x-2} ; p \leq$ 0.034). Also, their propensity to reciprocate tax policies decreases over time: the coefficient of $\left(t_{w, x-1}-t_{w, x-2}\right) \times 100 \times x$ if $l_{R, x-1}>l_{R, x-2}$ is positive in both regressions but it is significant only for high-tax societies ( $p=0.022$; for low-tax societies $p=0.289$ ). None of the 
coefficients are significantly different across the two regressions $(p>0.154)$, indicating that the observed tacit lobbying agreements in low-tax societies are not due to differences in the rich voters' propensity to reciprocate candidate behavior. Our findings are summarized in the next experimental result:

Experimental Result 4 (Tacit lobbying agreements and mutual reciprocation): With repeated interaction, on average, the two candidates reciprocate transfer increases by lowering their tax policies, and in return, the rich voter reciprocates decreases in winning tax policies by raising total transfers. In addition, tacit lobbying agreements arise when candidates coordinate on lower tax policies by reciprocating each other's tax policy. Finally, the propensity to reciprocate within the lobbying coalition tends to decrease over time.

\section{Tacit lobbying agreements and earnings}

In this final subsection, we analyze how tacit lobbying agreements (or the lack thereof) affect the observed earnings of voters and candidates. ${ }^{22}$ Recall that with zero transfers and full redistribution, the earnings per period are 40 points for each voter and an average 35 points for each candidate. As one would suspect, without the opportunity to lobby, mean earnings are very close to this benchmark. In Strangers-No Lobbying (Partners-No Lobbying), on average poor voters earn 39.4 (39.2) points, rich voters 41.9 (42.3) points, and candidates 34.9 (34.9) points. The picture looks different with lobbying opportunities. In Strangers-Lobbying, on average rich voters have lower earnings than in the benchmark (26.1 vs. 40 points) and candidates have higher earnings (43.0 vs. 35 points). In contrast, the mean earnings of poor voters are close to the 40-point benchmark (39.3 points). Clearly, this earning distribution is due to some unsuccessful lobbying attempts of rich voters. In Partners-Lobbying, candidates once again profit on average (41.0 vs. 35 points), but this time the poor voters lose (35.9 vs. 40 points) and the rich voters break about even (39.9 vs. 40 points). The shift in earnings towards rich voters and candidates is starker in societies with tacit lobbying agreements where, on average, poor voters earn considerably less than

\footnotetext{
22 Our analysis includes the cost of tax policy changes, but excluding this cost has virtually no effect on the results. The total costs make up at most $0.4 \%$ of the candidates' payoffs.
} 
in the benchmark (31.0 points) while members of the tacit agreement earn considerably more (rich voters earn 43.0 points and candidates 46.8 points). In contrast, in high-tax societies the mean earnings of all players are close to the benchmark (39.3 for poor voters, 37.8 for rich voters, and 37.0 for candidates). This gives our final result: ${ }^{23}$

Experimental Result 5 (Tacit lobbying agreements and earnings): With one-shot interaction, on average, lobbyists lose money to the candidates due to unsuccessful lobbying attempts and poor voters neither gain nor lose. With repeated interaction, on average, in societies without tacit lobbying agreements the earnings of lobbyists, candidates, and poor voters do not change, whereas in societies where tacit lobbying agreements emerge lobbyists and candidates gain at the expense of poor voters.

\section{Conclusions}

We experimentally study whether tacit lobbying agreements emerge in a strategic situation where a lobbyist can send money to two competing political candidates in order to influence redistributive tax policies. Importantly, candidates are not obliged to respond to lobbying and must consider their probability of winning upcoming simple-majority elections in which the lobbyist prefers zero redistribution and a majority prefers full redistribution. We compare situations with and without lobbying opportunities and situations with one-shot and finitely-repeated interaction.

We observe that tacit lobbying agreements arise in about $40 \%$ of societies with repeated interaction but never with one-shot interaction (in the latter treatment, despite some lobbying attempts, the experimental results are very similar to our treatments without the option to lobby). Thus, a substantial number of subjects make use of the opportunity to form tacit lobbying agreements at the expense of a majority. It is likely that

\footnotetext{
${ }^{23}$ Compared to the No Lobbying treatment, with Lobbying: the earnings of candidates are higher (for Strangers: $p$ $=0.003$, and for Partners: $p \leq 0.001)$, the earnings of poor voters are not significantly different in Strangers ( $p=$ 0.563) but are lower in Partners $(p=0.007)$, and the earnings or rich voters are lower in Strangers $(p=0.003)$ but are higher in Partners ( $p=0.084$, for low-tax societies $p=0.037$ ). The $p$-values are derived from Wilcoxon signed-ranks tests using society means as the unit observations.
} 
more subjects are willing to collude, but they are unable to overcome the many obstacles of the coalition-formation process. We find that mutual reciprocation between the lobbyist and the two candidates is the driving force behind the emergence and stability of tacit lobbying agreements (candidates reward increased transfers with lower taxes and the lobbyist rewards lower taxes with higher transfers). However, the success of lobbying not only requires reciprocity between the lobbyist and candidates but also between the two candidates (i.e., lowering their tax policy if the other candidate's tax policy is smaller than their own). Supporting our theoretical predictions, the experimental results indicate two main reasons why repeated interaction is necessary for tacit lobbying agreements to arise. First, unlike in one-shot encounters, with repeated encounters the lobbyist can reciprocate the tax policies of the candidates. Second, the opportunity to reciprocate across periods gives self-interested candidates an incentive to mimic conditional cooperators in anticipation of future profits.

Interestingly, in support of the external validity of our experimental results, we observe some similarities in the findings between the observational study of Richter, Samphantharak, and Timmons (2009) and this study. For example, both their Figure 2 (p. 899) and our Figure 2 show that firms that lobby (not all do so) profit on average and tax favors are negatively proportional to the size of the investments they make. Due to the nature of the observational data, Richter, Samphantharak, and Timmons (2009) focus their analysis mainly on the profitability of lobbying. In addition to profitability, our lobbying game and experiment allows us to examine the decision-making process underlying the formation of tacit lobbying agreements. We provide three reasons why in the field and laboratory many firms do not lobby. First, some firms and candidates are civic-minded, and hence, they have no intention to challenge the will of the majority. Second, even when willing to join a coalition, it is very difficult for potential colluders to overcome the substantial obstacles of reaching tacit lobbying agreements, which are not contractenforceable. Importantly, if firms and candidates expect to interact only for a short period of time, they have disincentives to collude. Third, they need to settle on one of the many possible tacit lobbying agreements, which determines how the joint profits are shared. 
The use of game theory and experiments to study lobbying can be extended to answer many questions that are not easily addressed with other methods. For example, one can design experiments to assess the effect of counteractive lobbying by the majority (see Austen-Smith and Wright 1994; Großer and Reuben 2010) or to study the impact of explicit communication between lobbyists and candidates. Future research could also investigate the effect of public information about lobbying transfers, i.e., one could focus on studying under-the-counter deals, which tend to be unobservable in the field. Finally, an interesting next step would be to study the effects of asymmetry (e.g., candidates with different policymaking capacities) on the ability of potential colluders to reach an agreement. Given the many possible extensions, this paper is a first step in a line of research that has the potential to give us fundamental insights on lobbying, the financially-dominant form of political contribution, and the complex process of buying political influence that shapes everyday policymaking.

\section{References}

Adams, John S. 1965. "Inequity in social exchange." In Advances in Experimental Social Psychology, Vol. 2. Academic: New York, 267-99.

Austen-Smith, David, and John R. Wright. 1994. "Counteractive lobbying." American Journal of Political Science 38 (2): 25-44.

Bental, Benjamin, and Uri Ben-Zion. 1975. "Political contribution and policy-Some extensions." Public Choice 19: 1-12.

Ben-Zion, Uri, and Zeev Eytan. 1974. "On money, votes, policy in a democratic society." Public Choice 17: 1-10.

Bolton, Gary, and Axel Ockenfels. 2000. "A theory of equity, reciprocity, and competition." American Economic Review 100: 166-93.

Dal Bó, Ernesto. 2007. “Bribing voters.” American Journal of Political Science 51 (4): 789803.

De Figueiredo, John M., and Brian S. Silverman. 2006. "Academic earmarks and the returns to lobbying." Journal of Law and Economics 49 (October): 597-625. 
Fehr, Ernst, and Simon Gächter. 2000. "Fairness and retaliation: The economics of reciprocity." Journal of Economic Perspectives 14 (3): 159-181.

Fehr, Ernst, and Klaus Schmidt. 1999. "A theory of fairness, competition and cooperation." Quarterly Journal of Economics 114: 817-68.

Fischbacher, Urs, Simon Gächter, and Ernst Fehr. 2001. "Are people conditionally cooperative? Evidence from a public goods experiment." Economics Letters 71(3): 397-404.

Fischbacher, Urs. 2007. "Z-tree: Zurich toolbox for ready-made economic experiments." Experimental Economics 10: 171-78.

Großer, Jens, and Ernesto Reuben. 2010. "Redistributive politics and market efficiency: An experimental study." Working paper.

Grossman, Gene M., and Elhanan Helpman. 1994. "Protection for sale." American Economic Review 84 (4): 833-50.

Grossman, Gene M., and Elhanan Helpman. 2001. Special interest politics. MIT Press: Cambridge, Massachusetts.

Hansen, Wendy L., Neil J. Mitchell, and Jeffrey M. Drope. 2005. "The logic of private and collective action." American Journal of Political Science 49 (1): 150-67.

Heinz, John P., Edward O. Laumann, Robert L. Nelson, and Robert H. Salisbury. 1993. The hollow core: Private interests in national policymaking. Cambridge, Massachusetts: Harvard University Press.

Hillman, Aye, and Heinrich W. Ursprung. 1988. "Domestic politics, foreign interests, and international trade policy." American Economic Review 78 (4): 729-45.

Hojnacki, Marie, and David C. Kimball. 1998. "Organized interests and the decision of whom to lobby in Congress." American Political Science Review 92 (4): 775-90.

Konow, James. 2003. "Which is the fairest one of all? A positive analysis of justice theories." Journal of Economic Literature 41: 1186-1237.

Kreps, David M., Paul Milgrom, John Roberts, and Robert Wilson. 1982. "Rational cooperation in the finitely repeated prisoners' dilemma." Journal of Economic Theory 27: $245-52$. 
Magee, Stephen P., William A. Brock, and Leslie Young. 1989. Black hole tariffs endogenous policy theory: Political economy in general equilibrium. Cambridge University Press: Cambridge, Massachusetts.

Mitchell, William C., and Michael C. Munger. 1991. "Models of interest groups: An introductory survey." American Journal of Political Science 35 (May): 512-46.

Milyo, Jeffrey, David M. Primo, and Timothy J. Groseclose. 2000. "Corporate PAC contributions in perspective." Business and Politics 2(1): 75-88.

Nownes, Anthony J., and Patricia Freeman. 1998. "Interest group activity in the States." Journal of Politics 60 (February): 86-112.

Rabe-Hesketh, Sophia, Anders Skrondal, and Andrew Pickles. 2005. "Maximum likelihood estimation of limited and discrete dependent variable models with nested random effects." Journal of Econometrics 128 (2): 301-23.

Richter, Brian Kelleher, Krislert Samphantharak, and Jeffrey F. Timmons. 2009. "Lobbying and taxes." American Journal of Political Science 53 (4): 893-909.

Schelling, Thomas C. 1960. The strategy of conflict. Cambridge, Mass.: Harvard University Press.

Schlozman, Kay Lehman, and John T. Tierney. 1983. "More of the same: Washington pressure group activity in a decade of change." Journal of Politics 45: 351-77.

Selten, Reinhard. 1978. "The equity principle in economic behavior." In Decision theory, social ethics, issues in social choice, eds. H.W. Gottinger and W. Leinfellner. Dordrecht: D. Reidel Publishing Company, 289-301.

Selten, Reinhard. 1987. "Equity and coalition bargaining in experimental three-person games." In Laboratory Experimentation in Economics, ed. A.E. Roth. Cambridge, MA: Cambridge University Press, 42-98.

Snyder, James M. 1992. "Long-term investing in politicians; or, give early, give often." Journal of Law and Economics 35 (1): 15-43.

Snyder, James M., and Michael M. Ting. 2008. "Interest groups and the electoral control of politicians." Journal of Public Economics 92: 482-500. 
Stigler, George. 1971. "The theory of economic regulation." Bell Journal of Economics and Management Science 2: 3-21.

Tullock, Gordon. 1972. "The purchase of politicians." Western Economic Journal 10 (September): 354-55.

Welch, William P. 1974. “The economics of campaign funds.” Public Choice 20 (1): 83-97. 